\title{
The Moral Virtue of Being Understanding
}

\author{
Eva-Maria Düringer ${ }^{1,2}$
}

Accepted: 25 August 2021/Published online: 5 September 2021

(C) The Author(s) 2021

\begin{abstract}
Being understanding is a moral virtue. But what exactly is it that an understanding person does excellently? And what exactly makes it a moral virtue, rather than (merely) an intellectual one? Stephen Grimm suggests that an understanding person judges other people's moral failings accurately without being too permissive or too judgemental. I argue against this view and develop an alternative one. First I demonstrate that judging other people's failures accurately is neither necessary nor sufficient for being understanding and that Grimm leaves the moral nature of being understanding underexplored. I then draw on a related discussion on the moral virtue of open-mindedness and argue that a virtue is a moral one when it is a corrective to selfish and other weak inclinations that pull us away from feeling and acting as the situation demands. In order to fill in what this means in the case of being understanding, I turn to Iris Murdoch's notion of attention. Being understanding, I argue, is the virtue of appropriately attending to others who are in a difficult situation.
\end{abstract}

Keywords Understanding · Moral and intellectual virtues · Open-mindedness · Iris Murdoch · Attention

Understanding people are people we like being around. We feel safe with them. We feel that they are willing to acknowledge where we are coming from, that they will allow for ways of reasoning that might not have been ideal yet were natural given the situation, and that they will still like us even though we might have done something a bit wrong. They are good people.

In this paper I want to pursue three questions: (1) what does being understanding consist in? It does not seem necessarily to consist in actually understanding others, given that people such as good analysts can understand others exceptionally well without being understanding at all. What then is it to be understanding? (2) In what way are understanding people good people? Are they particularly good at judging moral matters, do they possess a particular moral

Eva-Maria Düringer

eva-maria.dueringer@uni-tuebingen.de

1 Philosophy Department, University of Tübingen, Tübingen, Germany

2 Philosophisches Seminar, Universität Tübingen, Bursagasse 1, 72070 Tübingen, Germany 
motivation, or do they act and feel in a particular way? And (3), even though being understanding does not necessarily involve understanding others well, might there still be anything in particular of which only understanding people have a good grasp? I will devote most of the paper to the first two questions and speculate briefly about an answer to the third one at the end.

In the first section I will map the area by looking at common examples and discussing Stephen Grimm's characterisation of what it means to be understanding. I will argue that his account focuses too much on the epistemic activity of correctly judging other people's failures and too little on that which makes us describe understanding people as good people, rather than merely as clever or knowledgeable. I will show that being understanding need not have anything to do with judging failures at all. As a first approximation it seems to be best characterised as an appropriate response to people in difficult situations.

Given that one main problem with Grimm's account is that it does not satisfactorily explain the way in which being understanding is a moral, rather than a purely epistemic or intellectual virtue, I will turn to the discussion of a similar virtue in section two to see what can be learnt from it. Just like being understanding, open-mindedness cannot be reduced to a purely intellectual virtue because it manifests, in some instances at least, as a decidedly moral virtue. It is not my goal to provide clear demarcation lines between epistemic and moral virtues or even to say that this would be desirable. I will point out, however, that a focus that lies mainly on motivations outside a virtuous activity, e.g. the motivation to do what is right, or beneficial outcomes that result from it, is likely to miss the moral character of the virtuous activity itself. This can be observed in Nomy Arpaly's account of the moral nature of open-mindedness. I will demonstrate that Yujia Song's descriptions of the feelings and actions of an open-minded person bring out the moral aspect of open-mindedness in a much richer way. These descriptions fit well with the Aristotelian notion that the moral aspect of a virtue lies in its being a particular way of feeling and acting, i.e. of correcting selfish and other weak inclinations and working up motivations and actions that are called for in a situation.

I will turn again to the virtue of being understanding in the third section. Based on the insights of section two, I will give a description of the ways of feeling and acting, of correcting and enforcing motivations, that are characteristic of the understanding person on the basis of Iris Murdoch's notion of attention. Being understanding, I will argue, is excellently attending to people in difficult situations. In the fourth and last section I will briefly speculate on what, if anything, it might be that the understanding person grasps particularly well.

\section{Being Understanding}

What does being understanding consist in? Most commonly we tend to call people understanding when they react in a sympathetic, possibly forgiving way to confessions of bad behaviour. Think of a student who apologises to her professor for not having finished her essay on time because she had to work long shifts at work. When we say that the professor is very understanding about this, we mean that she somehow signals to the student that she acknowledges the difficulties of the circumstances and that she does not think badly of the student for having missed the deadline. We can imagine her saying things like, "Yes, it is hard being a full-time student and supporting yourself at the same time," and asking questions about the student's situation like "Do you often work long hours, does it often interfere with your studies, might there be a way for you to work shorter shifts?" She will make the student feel 
comfortable and give her the impression that she's on her side while trying to gain an insight into the student's true situation.

With this example in the background, let us look at Stephen Grimm's recent attempt to pin down being understanding. Grimm thinks of it as the mean between the excess vice of judgementalism and the deficiency vice of naïvete or permissivism (2019, p. 346). Had the professor not listened carefully to the student's explanations but simply judged her to be either lazy or intellectually not up to the mark, we'd have called her judgemental. Had she given her an extension despite believing that the student could have met the deadline had she partied less, we'd have called her permissive. Had she believed a cock and bull story about superhuman demands on the student outside campus without asking questions to get at the truth, we'd have called her naïve. Being understanding, according to Grimm, is something in between these extremes. The understanding person will "often be making judgments about the motivations and deficient character traits of others (and of him/herself). He or she will charitably try to interpret the motives and circumstances of others, while realizing that human beings often fall short of what justice requires" (ibid). Accordingly, as an understanding person, the professor is someone who charitably judges the failings of others, keeping in mind "our common frailty" (Grimm 2018, p. 117), knowing that it's a feature of human nature to be unable always to know what the right thing to do is and do it.

Grimm's characterisation of being understanding serves as a very good first approximation. Being understanding often and commonly is a matter of becoming clear on why someone acted the way they did in a sympathetic way, avoiding being too harsh and too soft on them. Yet Grimm's characterisation does not give us a full picture of what it means to be understanding. It suffers from two major shortcomings: (1) it does not bring out the way in which being understanding is a moral virtue, rather than a merely epistemic one, and (2) it is too restrictive in its mapping of the family of situations to which being understanding is the appropriate response. I will explain both shortcomings in turn.

No doubt charitably judging the moral failings of others is a central aspect of being understanding, but being understanding does not stop there. The professor certainly does judge the failure to meet the deadline charitably, i.e. after having gained a fair insight into the student's circumstances and against the background of the knowledge of the weaknesses of human nature quite generally. But if this were all there is to it, then she could have dismissed the student without further ado with a fail for having missed the deadline - and she would still have deserved praise for being understanding. This does not sit right, however. If all there was to being understanding was judging a case fairly, then being understanding would be compatible with all sorts of reactions to this fair judging: remaining unmoved by it, dismissing it as unimportant, applying the rules as one would have anyway, etc. But I don't think we would describe the professor as being understanding if, once she had gained a good insight into the circumstances, had simply said, "Well, there it is. I'll have to fail you, of course, but I see now why you failed." The student would not have told her friends that evening "I talked to my professor about my long shifts and she was totally understanding about the fact that I couldn't meet the deadline." I don't mean to say that someone who is understanding always pardons, always forgives, always finds ways of avoiding negative consequences. But she will, to some degree at least, be sorry about this, feel for the other, wish she could have helped. These impulses, feelings and motivations need to be worked into a characterisation of being understanding to make it satisfactory.

The problem that is thus emerging is that Grimm's description of being understanding makes it too much of an intellectual, or epistemic, and not enough of a moral virtue. Grimm 
calls it "a character-level virtue that interestingly combines moral and epistemic elements" (Grimm 2019, p. 341, my italics) and says that "the epistemic and moral faults in cases of judgmentalism will be so deeply intertwined" (Grimm 2019, p. 346, my italics). I entirely agree with him that being understanding possesses epistemic as well as moral elements and that it is not easy to say where the one element ends and the other begins. It is not my aim in this paper to draw a clear demarcation line. But we need to say much more about the moral element than Grimm does. If the moral element of understanding consisted in viewing different perspectives with "a sympathetic eye" (Grimm 2019, p. 341) and in interpreting motives "charitably", then one could take this minimalistically to mean that sympathy and charity are in place to ensure one reaches a justified true belief about another person's motives and actions. What one does with one's knowledge, how one thinks and feels about it and how one treats the other person once one has ascertained such knowledge, seem to be irrelevant on this minimalistic reading. But they are not irrelevant. As Yujia Song puts it in her criticism of overly intellectual readings of open-mindedness, "getting one's facts right does not guarantee right action" (Song 2018, p. 67). Perhaps we need not go as far as saying that "right action", whatever that may be, is necessary for a manifestation of being understanding. But a certain degree of goodwill and active interest are. Indeed, what we praise when we call someone understanding is not merely the clarity with which they pick out the exact nature of another person's failing, but the way they engage with her, the way they listen, the way in which they are interested. Perhaps Grimm means all this when he describes the understanding person as charitable and sympathetic. If he does, the task nevertheless remains: we need a fuller characterisation of this moral aspect of being understanding.

A related task concerns the description of the family of situations to which being understanding is the appropriate reaction. Because Grimm is too restrictive here, he misses the variety of shapes an appropriate reaction to these situations can take. All moral virtues are appropriate ways of dealing with, facing, and responding to a particular family of situations: courage is a response to situations of danger and threat, generosity to situations in which one is able to give, helpfulness to situations of encountering needs, and so on. Grimm's assumption is that being understanding is primarily a way of dealing with other people's moral failings. But this is too restrictive. Undoubtedly we most often talk of people as understanding when we report on how they handled confessions of bad behaviour of some sort or other, but not always. Think of a grieving person, Gerald, who has just lost his beloved wife after forty years of marriage and is suffering very much. His good friend Peter, himself a lifelong bachelor, comes to see him every other day and sits with him. Gerald might say in hindsight, "I'm so grateful Peter came round so often to check on me. He is so very understanding." What does this tell us about Peter? Peter certainly was not in the business of judging Gerald's moral failings. Admittedly, we can imagine Gerald having been unsocial and sometimes positively rude to Peter, given the circumstances. But these behaviours do not necessarily constitute a moral failing, and making judgements about, forgiving and tolerating them do not (mainly) constitute Peter's being understanding. Instead, Peter's being understanding is likely to have manifested in his general approach to Gerald: presumably he was present, but unobtrusively so. $\mathrm{He}$ probably signalled that he'd be there to listen, but did not worm his way into Gerald's confidence. There is also an epistemic element that differs from Grimm's judgements about moral failings: Peter presumably understood, in a vague and general way, that losing your beloved partner changes your world completely, makes you feel lost and unable and maybe even unwilling to see how your life might go on. He did not really know what was going through Gerald's head most of the time, nor did he have a proper grasp of the felt qualities of 
Gerald's grief. And he did not pretend to. But he was to some extent tuned into Gerald's needs and sensed how he could best meet, or work around, those needs at different times.

I hope this example shows that being understanding can be an appropriate way of dealing with situations where there are no moral failures to be judged at all, either charitably or otherwise. The family of situations to which being understanding is the appropriate response should thus be characterised more broadly than Grimm characterises it. Perhaps we can say, roughly, that being understanding is an appropriate response to people who are in a difficult situation. The label "difficult situation" here subsumes situations such as being in the grip of negative emotions such as grief, sadness, fear, or anger; suffering more broadly understood; being ill; worrying about something; facing difficult decisions; being anxious or depressed; feeling bad due to the knowledge that one has done something wrong; and simply having done something wrong. Being in a difficult situation does not require, I take it, that you're aware that you're in difficulties, nor does it require any uncomfortable feelings that usually come with being in difficulties. Let me give you two examples:

Imagine the girl next door has just turned 18 and is having a big a party. The music is much too loud and it's past midnight already. If your reaction is "Well, you're only 18 once," then you'll be understanding even though the girl is probably not aware of her wrongdoing. Your being understanding manifests as a simple act of pardoning a wrong on the basis of the acknowledgement of the fact that it's hard for all of us always to avoid thoughtlessness and inconsiderateness.

Next, think of President Obama when he was still in office, labouring over difficult decisions. Much hung on these decisions and Obama was aware that no matter what he decided, the ultimate outcome would be determined by factors impossible to predict with certainty. But, following a sound decision-making process, "one in which I was able to empty out my ego and really listen, following the facts and logic as best I could and considering them alongside my goals and my principles - I realized I could make tough decisions and still sleep easy at night" (Obama 2020, p. 239). Obama did not feel troubled by his difficult decisions, nevertheless we can and should have met his difficulties with being understanding. Here being understanding is an acknowledgement of Obama's great responsibility, a recognition of the immense difficulty of his work, that make us criticise his decisions less harshly than we might otherwise have done.

It might be objected that being in a difficult situation, though broader than Grimm's family of situations to which we respond with being understanding, is yet not broad enough. When your good friend tells you that she's in a new relationship for the first time after a long and painful divorce, you are very happy for her. You know how hard the last few years have been for her, how difficult it must be for her to open up and trust someone again, and thus rejoice with her in her newfound happiness. Would we not say that your reaction is one of being understanding? I'm not convinced we would, nor do I think we should. We would say other things instead: your reaction is very empathetic, shows fellow-feeling, is proof that you know her very well and care a lot about her. You indeed understand her very well, but understanding is not the same as being understanding. In ordinary language I take it that we use the phrase "being understanding" in the way described above, i.e. when appropriately responding to people in difficult situations. This is perhaps most obvious when we think about cases in which we accuse someone of not being understanding enough. We say things like "you really could be a bit more understanding" when we think you should be more attentive, forgiving or acknowledging of hardship, and not when we think you should rejoice more in someone else's good news. In the latter case we might say "Don't you understand what this means to her?", 
which is a different kind of criticism. In fact we can distinguish three criticisms. Firstly, we can criticise someone for not understanding someone else, i.e. for not grasping how they think and feel. Given a situation which calls for such understanding and in which such understanding could be achieved if one put one's mind to it, this is a manifestation of a primarily epistemic vice. Secondly, we can criticise someone for a lack of what Olivia Bailey calls "humane understanding" (Bailey 2020), which goes deeper than understanding that others think and feel a certain way. Additionally, we also grasp why they do. As Baily puts it,

The one who understands grasps the intelligibility of the outlook in which she is imaginatively immersed, and in so doing she also recognizes the other as one whose emotions are intelligible. That recognition is itself important to us, regardless of further consequences. We want to be seen as what we are: creatures whose emotions, however irrational they may be, nevertheless make perfect human sense. (Bailey 2020, p. 12)

We can thus fail in not understanding the way in which another person's thoughts and feelings make sense, which is already both an epistemic and a moral failure. It is a moral failure because humane understanding is something for which we have a profound need. Thirdly, we can criticise someone for not being understanding, a moral failure which is yet something over and above not understanding and not humanely understanding. By "over and above" I mean that being understanding ideally involves understanding and humane understanding, but when we criticise someone for not being understanding, we ask yet more of her. We ask her not only to acknowledge e.g. someone else's emotions as intelligible, but to offer something: a willingness to help, pardon, forgive, comfort, leave off criticising. And it is this last demand that we do not make on people who are not happy for others. They might be open to the first two criticisms, but not to the third. This is why I think we should restrict the family of situations to which being understanding is the appropriate response to those of people in difficulties.

I have just claimed that, ideally, someone who is being understanding also understands that and why another person thinks and feels a certain way. Let me qualify this a bit. It is possible to understand that and why a person thinks and feels a certain way without being understanding at all, and it is possible to be understanding without understanding that and why a person feels a certain way. One the one hand, the person who writes a psychiatric report about you may understand the workings of your mind very well, as do your siblings who've known you all their lives, yet they might fail to be understanding when you are in a difficult situation. They know quite well what you must be feeling and thinking and why, but they don't care. On the other hand, people who respond to calls on helplines, who don't know you at all, are being understanding when they are attentive and open, even though they might have difficulties grasping the trouble you're in. Undoubtedly a person being understanding must possess a willingness to (humanely) understand you and the situation you're in. Perhaps they must even generally be quite good at (humanely) understanding others. But they will still be understanding even if they fail to (humanely) understand you in your current situation. Exhibiting an honest interest, a lack of prejudgement and a willingness to comfort you is sufficient.

In this section I have claimed that Grimm's proposal of judging other people's failings accurately is neither necessary nor sufficient for being understanding. A broadened picture of the family of situations to which being understanding is the appropriate response has emerged, one which includes difficulties of various kinds. I will not say any more about this family of situations in what follows but presuppose what I have described above. Along with the broadened family of situations there has emerged a family of appropriate responses, too: it 
ranges from a simple pardoning of the other's actions and feelings (as in the birthday party case), an acknowledgement of hardships resulting in less harsh criticisms (as in Obama's case), to active support, whether by listening and trying to understand (as in the helpline case), by just being around (as in the case of Gerald and Peter), by giving someone the feeling that they're okay despite their failings, and by actually doing something to solve the problem that constitutes the trouble (as in the professor and student case). What is at the moral heart of all these responses will be the topic of the next two sections.

In the next section I will try to get a handle on the moral heart of virtuous responses more generally and look at a close relative of being understanding: open-mindedness. My aim is to show that the moral nature of a virtue is not sufficiently captured by pointing to a general moral motivation that encourages its manifestation, or to beneficial outcomes that manifestations of that virtue tend to have. The discussion of open-mindedness shows that we lose sight of important moral characteristics if we do this. We must look at the specific way in which a virtue is a corrective to our ways of feeling and acting from selfishness and other weaknesses to appreciate the virtue's moral nature fully.

\section{Open-Mindedness and What Makes Something a Moral Virtue}

It is very hard to provide clear criteria for the distinction between moral and intellectual virtues. As Heather Battaly (2013) demonstrates, there are good reasons to think that intellectual virtues are a subcategory of moral virtues, there are good reasons to think the opposite, and there are good reasons to think something in between. I do not want to go into this debate, nor do I think I have to, because I do not want to claim that being understanding is purely a moral virtue. Being understanding, as we have seen, involves the epistemic willingness to understand another person and their situation. It is thus a virtue that, to recall Grimm's formulation, interestingly combines moral and epistemic elements. Nevertheless, I do want to get clearer on these moral elements and thus need to carve them out.

It seems that there are two dominant answers to the question of what makes a virtue a moral virtue: we can say either that there are one or several motivations to act on certain dispositions that make these dispositions moral virtues. Alan Wilson (2017) suggests kindness and justice as such master motivations, a Kantian suggestion here would point to a strong will to do one's duty as a master motivation. Or we can say that certain dispositions reliably lead to beneficial outcomes and this is what makes these dispositions moral virtues (e.g. Driver 2003). Again, this is not a debate I want to get into too deeply here, but I will have to touch on it.

I take it that there is more to the moral nature of a virtue than being demanded by an external moral motivation or reliably producing beneficial outcomes. Philippa Foot says of virtues that they are a "corrective, each one standing at a point at which there is some temptation to be resisted or deficiency of motivation to be made good" (Foot 1978, p. 8). This is of course very close to Aristotle's original definition of moral virtues:

virtue must have the quality of aiming at the intermediate. I mean moral virtue; for it is this that is concerned with passions and actions, and in these there is excess, defect, and the intermediate. For instance, both fear and confidence and appetite and anger and pity and in general pleasure and pain may be felt both too much and too little, and in both cases not well; but to feel them at the right times, with reference to the right objects, 
towards the right people, with the right motive, and in the right way, is what is both intermediate and best, and this is characteristic of virtue. (1106b)

Admittedly, Aristotle speaks here of "the right motive", but this does not seem to point to a general moral concern you should have, but again to the intermediate, or best, given the situation: e.g. when you're angry with your daughter and tell her off, then this should be done with the motive of making her see where she went wrong, and not with the motive of humiliating her. Aristotle marks out virtues as moral when they are "concerned with passions and actions", and are the intermediate and best ways of feeling and doing. In all passions and actions there are excesses and defects. Correcting such excesses and defects and enabling appropriate feelings and actions is that which moral virtues are concerned with. And with such correctives in place, the moral motivation to do one's duty should be mostly superfluous and beneficial outcomes don't seem necessary to give them a moral nature.

The claim I want to work with, then, is that the moral nature of a virtue lies in its being a corrective of specific selfish and other weak indulgences; a corrective that enables us to see, feel and act as the situation requires. I argue for this here only by demonstrating how well this definition manages to carve out what is morally distinctive about open-mindedness and being understanding. In this section I will first look at Nomy Arpaly's take on open-mindedness and show that her focus on moral concern as the external motivation that makes open-mindedness a moral virtue is not satisfactory. Drawing on Yujia Song's criticism of Arpaly I demonstrate that the notion of moral virtues as correctives does a more satisfactory job. I use these insights to provide a first sketch of the moral nature of being understanding, which I will continue to fill out in the next section.

Arpaly (2011) argues that the moral virtue of open-mindedness consists in a willingness to consider and reconsider other viewpoints that is motivated by moral concern. You possess the moral virtue of open-mindedness if you are open to other viewpoints because you want to do the right thing. She uses the example of Ignaz Semmelweis to illustrate this. When Semmelweis found out that the disinfecting of hands drastically reduces childbed fever, he was not believed by his colleagues. On the contrary: he was ridiculed, dismissed and not taken seriously as a scholar anymore. Why was this? Semmelweis's colleagues were close-minded, but in this case, according to Arpaly, this was not merely an intellectual vice, but also a moral one. This was so because the underlying motivation was immoral. In their approach to new theories about the prevention of childbed fever, Semmelweis's colleagues were not sufficiently driven by moral concern, and much too driven by concerns about their reputation and not wanting to face having caused many a mother to die because of the germs they had on their hands. Had they cared enough about doing what is right, they would have put selfish concerns to one side and looked at Semmelweis's carefully collected empirical data.

Arpaly's approach to identifying the moral aspect of open-mindedness thus lies in identifying a particular motivation we can have for being open-minded, i.e. the motivation of moral concern. As mentioned above, such a move is not uncommon, and certainly a person who wants to do what is right will be open-minded and deserves moral praise for this. But a person who does not think much about wanting to do what is right but is open-minded whenever the situation calls for it is no less praiseworthy. Indeed, we tend to think of people to whom moral virtues are second nature as especially praiseworthy. If this is not wrong, then there must be something moral in the very practise of these virtues. I'd like to find out what this is in the case of open-mindedness. 
In her critique of Arpaly's position, Song gives us the example of Daryl Davis, an AfricanAmerican musician who sought out the company of Ku-Klux-Klan members and ended up becoming friends with some. Why is an open-mindedness such as Davis's laudable?

He could have easily dismissed the idea of initiating conversation when he had the chance to, for he already knew the Klan's position on race, and that it is wrong (not to say that its views are a personal attack on him). It is against this background that his willingness to engage with the Klan members and their points of view stands out as particularly admirable. (Song 2018, p. 68)

According to Song open-mindedness is a moral virtue when it is a "willingness to be engaged in some way with the object. By this I mean taking an interest in, or paying attention to, the object instead of being indifferent, and exploring ways in which one may relate to it" (Song 2018, p. 72). The open-minded person gives another "full recognition ... as they moved from a default standpoint that favors dissociation to one that makes room for those individuals" (Song 2018, p. 75).

In Song's description Davis's open-mindedness manifests in his successful regulation of desires for dissociation with a hurtful and disrespectful person, and of feelings of ill will, as well as in his managing to work up a strong enough motivation to seek connections with that person. These then are some of the temptations an open-minded person needs to work against when she meets someone who thinks, perhaps profoundly, differently to herself: feelings ranging somewhere between disinterest and contempt, motivational pulls towards increasing the physical and personal space to that person, inclinations to ridicule or drown in meaninglessness what you take to oppose your own view in the other person's view. It sems to me that these are all defective ways of responding in such a situation. What would excessive ways of responding be? We could give in to a nosiness that makes us enquire into the last corners of someone else's mind that they might prefer to keep private, or to a missionary approach which thinly reveals, perhaps even to ourselves, a negative pre-judgement of the other's value and belief system. I think we now begin to see what open-mindedness as a moral virtue is: a keeping-in-check of feelings of arrogance, contempt for others and self-importance with regard to our own value and belief system, an appropriate regulation of feelings of curiosity that might otherwise make us tactless, and a working up of an appropriate and motivating interest in another person.

Daryl Davis's example clearly demonstrates the moral side of open-mindedness. How does Arpaly's example of Ignaz Semmelweis compare? It seems to me that, contrary to Davis, Semmelweis's example clearly demonstrates the intellectual side of open-mindedness rather than the moral, and that the moral virtues at play here were those of, say, courage, taking responsibility and integrity. Semmelweis had collected data that suggested new mothers died more often when they were examined by a physician who had examined a dead body before and not washed their hands. Open-mindedness here is nothing but the intellectually virtuous reaction to new data that won't fit with standard theories. As an intellectually virtuous agent, one has to either adjust the theories or find a fault with the data. Semmelweis couldn't do the latter, so he did the former. Given that doing the former came with a huge burden of regret for his whole profession, as it meant physicians had on a large scale caused the deaths of patients who might otherwise have survived, it took an enormous amount of responsibility, courage and integrity to go through with it. Undoubtedly, Semmelweis exhibited responsibility, courage and integrity. Just as undoubtably these are moral virtues, and Semmelweis deserves the highest moral praise for exercising them in this 
situation. But it seems that these were the moral virtues in play here, called for by an intellectually virtuous act of open-mindedness.

What we can take from this discussion is this. When we want to bring out the moral nature of a virtue that is also intellectual, it is very easy and tempting to view the intellectual aspect as central and add to it either a moral motive, such as moral concern in Arpaly's case, or a moral result, such as perhaps moral knowledge in Grimm's case. But these strategies seem to miss what is moral in the practise of a virtue itself, i.e. that it keeps in check particular selfish and otherwise weak temptations and makes sure we are motivated appropriately given the situation.

Where does all this leave us with the moral nature of being understanding? We need to identify the weaknesses that need correcting to make sure that we feel and act appropriately with respect to people who are in a difficult situation. Let me end this section with a rough attempt at identifying these weaknesses before moving on to a more fine-grained attempt in the next section. Uncorrected weaknesses result either in deficient or excessive ways of feeling and acting with regard to a specific situation. Deficient ways of feeling and acting with respect to a person in a difficult situation include indulgences in concerns about our own comfort, e.g. when we don't answer the phone when a lonely relative is calling because we'd much rather watch a film with a glass of wine, when we come up with overly general pieces of advice because we are not really interested in a particular case, when we are constantly looking for aspects in the other person's narrative that we can use as prompts to talk about similar experiences that we've once had; but also indulgences in concerns about the other person's comfort, e.g. when we are too quick to excuse a wrong-doing that the other person should really take more time to think about and make amends for. Excessive ways of feeling and acting in such situations include prying into their difficulties in ways that are additionally hurtful, and suggesting a great variety of courses of action that we think may help but that are in fact overwhelming. The mean between these vices, the best way of feeling and acting with regard to a person who is in a difficult situation, is thus to try to gain an insight with a view to helping without being intrusive, to excuse what is excusable and to be constructive with regard to making amends or solving the problem, and where there are no solutions to be found, to want to comfort, to attend closely. This is what the understanding person does. In order to flesh out this virtue and get a richer description of this way of closely attending, I will turn to Iris Murdoch's notion of seeing lovingly in the next section.

\section{Murdoch's Attention}

Murdoch's central idea is that our moral aim in life is to attend, or, as she calls it, see lovingly. Seeing an object lovingly is equivalent to seeing it as it really is. It is not easy to see lovingly. We need to make sure that our usual ways of looking at the world, which ensure that the people and situations in it flatter and don't hurt us, are not in operation. We need to beat the "fat relentless ego" (Murdoch 2014/1971, p. 51) and the way it colours our perception. We also need properly to attend to the other. Murdoch takes her notion of attention from Simone Weil, for whom "the attentive mind is receptive but not seeking; that is not trying to understand, but to make itself available for understanding to occur" (Panizza 2017, p. 350). Panizza talks helpfully of the active and passive element of attention. The active one makes sure there are no distortions, the passive one is patient: it waits, is receptive for what may come and refrains from applying possibly unfitting categories of understanding to the new object. 
The famous example Murdoch uses to illustrate how one can achieve seeing lovingly is that of a mother-in-law, M, and her daughter-in-law, D. Initially M thinks of D as a silly, vulgar girl and of her son as having married beneath him. However, M "is an intelligent and wellintentioned person, capable of self-criticism, capable of giving careful and just attention to an object which confronts her" (Murdoch 2014/1971, p. 17). Being actively attentive, M acknowledges that her way of looking at D so far has never been just. D is of a different generation in which they do things differently, also she is aware that she is jealous of the woman who married her son (and would have been, no matter who the woman might have turned out to be). So M makes herself look again, makes herself attend passively: she finds that $\mathrm{D}$ is "not vulgar but refreshingly simple, not undignified but spontaneous, not noisy but gay, not tiresomely juvenile but delightfully youthful, and so on" (ibid).

Actually, if we accept that an understanding person reacts appropriately to another person who is in a difficult situation, then $\mathrm{M}$ and $\mathrm{D}$ is not a good example. $\mathrm{D}$ is not in a difficult situation; in fact, the example is set up such that D is even absent at the time $\mathrm{M}$ begins to "look again". But let us tweak the example a bit and I think we will gain valuable insights. Imagine D has done something about which she feels very bad and $\mathrm{M}$ has found out about it and seeks a conversation. Say D has gambled away a substantial sum of her husband's money. The old M will react triumphantly. She will seek a conversation so she can wallow in her newfound power, accuse D of always having had the wrong tastes and taken pleasure in the wrong things, of lacking responsibility and seriousness and being utterly and completely unworthy of her son. What will the new M do? She will be understanding. She will have managed to lose her self-protective way of viewing D's habits, she will be worried about the possible dissolution of an otherwise happy marriage, she will want to learn the details of the gambling history, see if there's an addiction that can possibly be treated, find out if she can help financially. All this will make her attend to D, sit quietly by her, be receptive, signal that she is not angry but, if anything, willing to help.

Another example from Murdoch helps to get the notion of attention still clearer. Here she talks about the attention involved in learning a new language:

Attention is rewarded by a knowledge of reality. Love of Russian leads me away from myself towards something alien to me, something which my consciousness cannot take over, swallow up, deny or make unreal. The honesty and humility required of the student - not to pretend to know what one does not-is the preparation for the honesty and humility of the scholar who does not even feel tempted to suppress the fact which damns his theory ... Developing a Sprachgefühl is developing a judicious respectful sensibility to something which is very like another organism. (Murdoch 1971/2014, p.

The active element of attention makes sure the learner does not "take over, swallow up, deny or make unreal" her object. What does Murdoch mean here? How can we try to learn a language in such a way as to make it unreal? I think she means that we can bend and twist it so as only to serve our needs. We can learn only as much as we need to order a glass of beer in a bar, or we can learn a foreign alphabet merely with the aim of impressing certain people at the next party. These could be classed as cases of denying a language, because we shut out the language as such and merely look at a tiny portion of it with the view of enhancing our own pleasures. Or we could, as we learn, dismiss difficult aspects - cases that don't exist in our native language, phrases that in literal translation don't make sense, sounds that we find very hard to pronounce - and speak the new language as if they didn't exist, not mindful of our 
incompetence. These could be instances of taking over a language. If added to all this is a consciousness governed by the belief that sufficient justice has been done to the language, I think we might have a case of having made the language unreal. Our consciousness has then "swallowed" it up. We have subordinated it to our own reality, act like we are its master, and don't acknowledge its existence beyond our mastery of it. It has lost, or rather we have lost, its identity.

The passive element of attention lets the learner really look. Love for an object "leads me away from myself towards something alien to me" and is "rewarded with a knowledge of reality". It requires "honesty and humility" and, if I manage to sustain my loving attention long enough and possess a bit of linguistic talent, is rewarded with Sprachgefühl, a feeling for the new language that goes far beyond the ability to translate literally. Sprachgefühl is a "judicious respectful sensibility" for the new language containing not only grammatical and pronunciational mastery but an intuitive sensibility for the way in which feelings and situations are expressed in it. Sprachgefühl is something very hard to attain for non-native speakers and yet acknowledged by the language lover as that what really speaking a language means. The language lover acknowledges having Sprachgefühl as a beautiful and intricate art, worthy of trying to develop whilst being humbly aware of her limitations.

In what way is attending to a language in this way similar to attending to another person? It is similar in both active and passive aspects. The active aspect in both cases involves resisting the distorted light my ego sheds on the other and instead submitting to the authority of the reality of the other. This means I need to fight all attempts of viewing the other in ways that suit myself, that make it easy for me, that shield me from nagging worries and the tedious work of being patient. Just as I mustn't make the new language unreal, I mustn't make the other person or their difficulties unreal. And this is something we indeed do all the time: when we are quick to think that a friend who just lost his job "will be alright", when we tell our wearisome relative on the phone that we have got to go because we're cooking, even though we simply cannot be bothered to listen, or when we listen to a friend's story only to find prompts to talk about our own experience. All these are everyday occurrences, all these are cases of making other people unreal. As is the case of M. Demeaning another who we experience as a threat, of whom we are jealous or who we envy, is another very common way of making another unreal because it makes us feel better, safer, more at ease.

The passive aspect of attention, both in approaching another language and in approaching another person, lies in being receptive and in really looking. We can prepare and cultivate the ground for being receptive by regularly asking ourselves questions: do we really understand what we think we understand? Should we not rather stand back once more? Really looking includes the attempt to view the object from perspectives other than my own. As a language learner I look at how competent speakers speak the language; as M I might look at how those who are close and possess goodwill towards D look at D. What does my son see in her, what might have prompted him to fall in love with her? But perhaps this is dangerous territory for M. She could try to alter her own perspective by imagining how she would have viewed D if D hadn't married her son but was simply another friend of her daughter's. She could try to see what D's good friends see in her. Or she could, and this surely is the hardest exercise, simply look. With all the feelings of jealousy and superiority in check, what does she see? She has to be patient, wait, not judge what she does not understand, not try to understand before she has really seen. If she is successful, then this will be the result: 
Her seeing of $\mathrm{D}$ is now more responsive to $\mathrm{D}$, meaning that the reality of $\mathrm{D}$ now shapes her seeing of D to an extent it previously did not. The way she now sees D is thus more open - more exposed - to the reality of D, and this is precisely the form or mode of her vulnerability to D. (Cordner 2016, p. 211)

We are now moving into the territory of what it means to get a feeling for another person, to see their reality. It can be a painful process, not only because I might see the other in all their glory, in all they are that I am not, in all they have that I do not, but also because I am now open to their worries, anxieties and sufferings. Attention can come at a high emotional cost. Beating the fat relentless ego takes away our defences and makes us vulnerable, and really looking lays us open to the emotional world of others. As David Velleman puts it:

Many of our defenses against being emotionally affected by another person are ways of not seeing what is most affecting about him. This contrived blindness to the other person is among the defenses that are lifted by love, with the result that we really look at him, perhaps for the first time, and respond emotionally in a way that's indicative of having really seen him. (Velleman 1999, p. 361)

Responding emotionally to another person, letting ourselves be affected, will often come with motivational pulls. We see that help is called for: perhaps we can do something to make things right, perhaps we can give some comfort by listening or just being there. With these motivational pulls our defences are called back to the scene, too. After all, listening to and being there for someone are hardly the kinds of activities we look forward to when planning the weekend ahead. "Surely it's not all that bad," we tell ourselves, or "a bit of time to themselves will do them good," or we silence our conscience by practising entirely insufficient acts of kindness such as sending an encouraging text or a pretty card. Also, were we to start listening and being there now, we might realise that there were many times in the past when we did not listen and were not there. In finally seeing the loneliness and deep sadness of my relative who lives alone, I also see that I contrived to not see this for the past twenty years. This is hard, as is being affected by her deep sadness, as is giving up my weekend pleasures to sit by her and make effortful conversation. Yet this is what a good person does.

How exactly does this examination of Murdoch's notion of seeing lovingly help us to get a richer description of that which the understanding person feels and does? My claim is that the understanding person sees lovingly another person in a difficult situation. She attends to her in the ways described above: in the way we imagined $\mathrm{M}$ to attend to D in the example of D's gambling problem, in the way we should attend to our lonely relative. She successfully keeps in check her selfish construal of the other person's troubles by not succumbing to inclinations such as wanting to avoid boredom and unpleasantness, making herself believe that attending will be fruitless anyway, letting her shyness rule the situation and being worried about what others might think of her if she lends her ear to this person. This forms the active component, the corrective element, of being understanding. The passive component builds on the active one. The understanding person successfully attends to the other person's troubles and by thus attending lays herself open to these troubles and what they mean to the other. She lets herself be affected by them, and this very affectedness prompts her to want to help and ideally shows her how best to do it.

This description sits well with our examples of understanding people from section one. The understanding professor does not give in to, and perhaps positively fights, prejudices and ways of thinking that might save her time. She does not put the student down as lazy and does not 
give her an extension simply because she's asked for one. Instead, she takes time to listen to the student's story, is interested in how the student's working hours truly affect her life and studies, and is ready to help find the best possible solution to the problem. Something similar is true of Peter in his approach to Gerald. Peter does not give in to, and perhaps positively fights, inclinations that, if acted upon, would make life easier for him, such as the aversion to the gravity of being around a grieving person and the preference for spending his time reading biographies and watching documentaries over effortfully generating the patience to be around a sad and silentman. Instead, he attends to Gerald, tries tactfully to see which needs he might be able to meet, is respectful of the dimension of suffering he knows he won't be able to grasp, makes sure to signal to Gerald that he is there no matter what because he knows that at least this, little as it is, will help a bit. The other examples of Obama's difficulties or the girl celebrating her 18th birthday with music that is too loud are of course much less demanding, yet they both essentially involve looking lovingly. They involve resisting complacent quick judgements such as "I'm sure Obama has lots of advisers who make the decisions for him and would get the blame if it goes wrong," or "how inconsiderate young people are today," and a positive appreciation of the difficult complexities in Obama's case and the thrill of finally coming of age which might make one forgetful of what is owed to one's neighbours in the party case.

Let me end this section by considering an objection. Even if you agree that Murdoch's notion of seeing lovingly helps to get a richer characterisation of being understanding, you might ask whether this focus on seeing things as they really are is not, after all, an intellectual, or epistemic activity and ill serves the project of carving out the moral element of being understanding. Seeing lovingly is indeed an intellectual activity aimed at grasping someone else's reality, but it is an intellectual activity performed lovingly. This is where its moral nature comes in and this is how the moral and epistemic elements are "so deeply intertwined" in being understanding. The understanding person wants to see, to understand someone else and their difficulties, but she does not necessarily need to do this successfully in order to be understanding. The way in which the understanding person tries to see the other is where the moral element comes in. The understanding person corrects selfish and other weak inclinations that might distort her vision and she keeps on looking even when what she sees begins to make demands on her, even heavy demands. This is a moral effort, a moral activity that does not come easily to many of us and that we need to practise much more than we do.

\section{The Moral Insight of the Understanding Person}

I have spent most of this paper trying to get a clearer picture of what it is that the virtue of being understanding consists in and in what way it is a moral, rather than a (purely) intellectual virtue. As mentioned in the introduction, there is another question to which I would like to try and give an answer, albeit very sketchily: apart from, ideally, understanding what other people feel and why, is there anything in particular the understanding person understands?

It strikes me that someone who has truly mastered the moral virtue of being understanding will come to an insight that only the constant excellent practise of being understanding affords. This insight is, in the words of Murdoch, "the extremely difficult realization that something other than oneself is real" (Murdoch 1999, p. 215). As understanding people, we have the deep, felt insight that there are utterly separate, different ways of engaging with the world. By constantly fighting inclinations that would otherwise make us dismiss such different ways of 
engaging with the world - the inclination to ridicule, to neglect, or to want to govern themand by constantly and humbly attending to what is revealed to us of the inner life of others, we come to allow them their rightful place. We come to experience that otherness is real and that being an other is as legitimate as being a self. Murdoch claims that "Love is the imaginative recognition of, that is respect for, this otherness" (Murdoch 1999, p. 216). Perfecting the virtue of being understanding is a way of loving in just this way and gaining the insights that such a love affords.

Acknowledgements I would like to thank the DFG (Deutsche Forschungsgemeinschaft) for generously funding the project "Natural Badness: Suffering and its Role in Contemporary Virtue Ethics", which allowed me to conduct the research for this paper. I am greatly indebted to two anonymous referees for extremely helpful and constructive feedback. I'd like to acknowledge in particular the Obama example, as well as prompts to reflect more on why we do not call people understanding when they rejoice in other people's good news and to clarify what is moral about Murdoch's notion of seeing. I also benefitted greatly from comments on earlier drafts of this paper by Robin Dennis, Jean-Moritz Müller, and Christiana Werner (to whom I owe the birthday example). Furthermore, I would like to thank the organisers and members of the DFG network "Feeling and Understanding" for providing an excellent atmosphere of discussion and many helpful questions and comments. I would also like to thank Sabine Döring, Irina Schumski, Daniel Zimmermann and the participants of the graduate seminar at the Philosophy Department of the University of Tübingen for avery helpful discussion of the ideas presented here. Finally, I would like to thank Rachael Wiseman for pointing me in the direction of Iris Murdoch.

Code Availability n/a

Funding Open Access funding enabled and organized by Projekt DEAL. The research for this paper was conducted with generous support of the DFG (Deutsche Forschungsgemeinschaft).

Data Availability n/a

\section{Declarations}

\section{Conflicts of Interest/Competing Interests n/a}

Open Access This article is licensed under a Creative Commons Attribution 4.0 International License, which permits use, sharing, adaptation, distribution and reproduction in any medium or format, as long as you give appropriate credit to the original author(s) and the source, provide a link to the Creative Commons licence, and indicate if changes were made. The images or other third party material in this article are included in the article's Creative Commons licence, unless indicated otherwise in a credit line to the material. If material is not included in the article's Creative Commons licence and your intended use is not permitted by statutory regulation or exceeds the permitted use, you will need to obtain permission directly from the copyright holder. To view a copy of this licence, visit http://creativecommons.org/licenses/by/4.0/.

\section{Bibliography}

Aristotle: Nichomachean Ethics, transl. by David Ross (2009). Oxford: Oxford University Press

Arpaly N (2011) Open-mindedness as a moral virtue. Am Philos Q 48(1):75-85

Bailey O (2020) Empathy and the value of humane understanding, Philos Phenomenol Res, pp 1-16

Battaly H (2013) Are moral and intellectual virtues distinct?, 2013 world congress proceedings, 68, Philosophy of Values

Cordner C (2016) Lessons of Murdochian attention. Sophia 55:197-213

Driver J (2003) The conflation of moral and epistemic virtue. Metaphilosophy 13:367-383

Foot P (1978) Virtues and Vices. Blackwell, Oxford 
Grimm S (2018) The Ethics of Understanding, in Making Sense of the World, ed. by Stephen Grimm, Oxford: Oxford University Press, pp. 116-34

Grimm S (2019) Understanding as an Intellectual Virtue, in The Routledge Companion to Virtue Epistemology, edited by Heather Battaly, pp. 340-51

Murdoch I (2014/1971) The sovereignty of good. Routledge, Abingdon

Murdoch I (1999) Existentialists and mystics: writings on philosophy and literature. Penguin, New York

Obama B (2020) A promised land. Random House, New York

Panizza S (2017) A Secular Mysticism? Simone Weil, Iris Murdoch and the Idea of Attention. In M. del Carmen Paredes (ed.), Filosofia, arte y mística. Salamanca, Spain: Salamanca University Press

Song Y (2018) The moral virtue of open-mindedness. Can J Philos 48(1):65-84

Velleman D (1999) Love as a moral emotion. Ethics 109(2):338-374

Wilson AT (2017) Avoiding the conflation of moral and intellectual virtues. Ethical Theory and Moral Practise 20:1037-1050

Publisher's Note Springer Nature remains neutral with regard to jurisdictional claims in published maps and institutional affiliations. 